\title{
Phylogenetic clustering of wingbeat frequency and flight-associated morphometrics across insect orders
}

\author{
by Tercel, M.P.T.G., Veronesi, F. and Pope, T.W.
}

Copyright, Publisher and Additional Information: This is the author accepted manuscript. The final published version (version of record) is available online via Wiley. This article may be used for non-commercial purposes in accordance with Wiley Terms and Conditions for Self-Archiving.

Please refer to any applicable terms of use of the publisher.

DOI: https://doi.org/10.1111/phen.12240

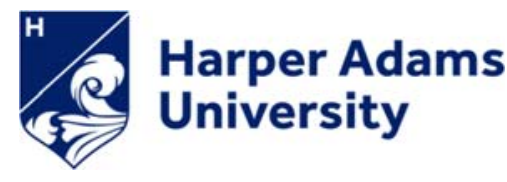

Tercel, M.P.T.G., Veronesi, F. and Pope, T.W. 2018. Phylogenetic clustering of wingbeat frequency and flight-associated morphometrics across insect orders. Physiological Entomology. 


\section{Title}

2 Phylogenetic clustering of wingbeat frequency and flight-associated morphometrics across

3 insect orders

4

\section{$5 \quad$ Running title}

$6 \quad$ Flight strategies between insect orders

7

8 Authors

9 Maximillian P. T. G. Tercel*, Fabio Veronesi and Tom W. Pope

10

11 Affiliation

12 Department of Crop and Environment Science, Harper Adams University, Newport,

13 Shropshire, TF10 8NB, UK.

14

15 *Author for correspondence (max.tercel@hotmail.com)

16

17

18 KEY WORDS: Comparative morphology, wing loading, body mass, flight strategy, insect

19 evolution, high-speed filming.

20

21

22 


\section{Summary statement}

24 Insect flight strategy varies between orders but is generally well conserved within orders, this

25 has important evolutionary and ecological implications at high taxonomic levels.

27 ABSTRACT

28 Wingbeat frequency in insects is an important variable in aerodynamic and energetic analyses of insect flight and has been studied previously on a family- or species-level basis. Meta-analyses of these studies have found order-level patterns that suggests flight strategy is moderately well conserved phylogenetically. Studies incorporated into these metaanalyses, however, use variable methodologies across different temperatures that may confound results and phylogenetic patterns. Here, a high-speed camera was used to measure wingbeat frequency in a wide variety of species $(n=102)$ in controlled conditions to determine the validity of previous meta-analyses that show phylogenetic clustering of flight strategy and to identify new evolutionary patterns between wingbeat frequency, body mass, wing area, wing length, and wing loading at the order level. All flight-associated morphometrics significantly affected wingbeat frequency. Linear models show that wing area explained the most amount of variation in wingbeat frequency $\left(R^{2}=0.59, \mathrm{p}=<0.001\right)$, whilst body mass explained the least $\left(R^{2}=0.09, \mathrm{p}=<0.01\right)$. A multiple regression model incorporating both body mass and wing area was the best overall predictor of wingbeat frequency $\left(R^{2}=0.84, p=<0.001\right)$. Order-level phylogenetic patterns across relationships were consistent with previous studies. Thus, the present study provides experimental validation of previous meta-analyses and provides new insights into phylogenetically conserved flight strategies across insect orders. 


\section{INTRODUCTION}

49 Wingbeat frequency in insects varies with body mass and wing area within and between 50 species (Byrne et al., 1988; Dudley, 2000), from $5.5 \mathrm{~Hz}$ in the helicopter damselfly 51 Megaloprepus caerulatus (Rüppell and Fincke, 1989) to over $1000 \mathrm{~Hz}$ in a ceratopogonid 52 Forcipomyia sp. midge (Sotavalta, 1953). How frequently an insect beats its wings is an 53 important variable when considering the biomechanics and physiology of insect flight 54 (Ellington, 1984a-f; Dudley, 2000; Alexander, 2002; Vogel, 2013). For any given body mass, 55 variables such as wing length, wing area, wing loading (body mass/wing area), wingbeat 56 frequency and stroke amplitude can differ substantially and affect the energetics and 57 biomechanics of insect flight, which is usually linked to evolutionary history (Byrne et al., 1988). 58 Stroke amplitude, the angle between the points of wing reversal, has been shown to vary between taxa, from $66^{\circ}$ in syrphids (Ellington, 1984c) to $180^{\circ}$ in beetles (Atkins, 1960) and 60 moths (Wilkins, 1991) and may vary significantly during a single flight as shown in dragonflies 61 (Alexander, 1986), orchid bees (Dudley, 1995; Dillon and Dudley, 2004), and fruit flies 62 (Lehmann and Dickinson, 1998; Fry et al., 2003). Though undeniably important to understanding insect flight strategy and aerodynamics, stroke amplitude was not measured in the current study. This is because although both wingbeat frequency and stroke amplitude change during a single flight, wingbeat frequency is kept relatively constant because of the high energetic cost of deviating from the resonant frequency of the flight apparatus (Dudley, 2000). Conversely, stroke amplitude may be altered extremely rapidly to change direction (Fry et al., 2003) or flight mode e.g. from hovering to forward flight (Dillon and Dudley, 2004). Because of this variability, stroke amplitude is likely to be a slightly less reliable indicator of flight strategy than wingbeat frequency.

71 The variables that influence the energetic and biomechanical aspects of flight could be used 72 to broadly characterize flight strategies between different orders of insects. Typically, higher wingbeat frequencies are associated with insects of smaller size, to overcome the increasingly viscous forces of the air present at small spatial scales, represented by low Reynolds numbers 
$75 R e$ in the order of 10-100 in the smallest insects (Ellington, 1999; Wang, 2005), and to better

76 control their direction in a windswept world (Vogel, 2013). Furthermore, frequencies of $>100$

$77 \mathrm{~Hz}$ are facilitated by asynchronous, or myogenic, flight muscle present in endopterygote

78 (Coleoptera, Diptera, Hymenoptera) and exopterygote (Thysanoptera and Hemiptera) groups

79 (Dudley, 2000) where one nerve impulse can initiate several wingbeats through stretch-

80 activation caused by mechanical loading on the wing (Pringle, 1967). Thus, the highest

81 wingbeat frequencies are found in smaller members of these groups (Byrne et al., 1988).

82 Members from other orders possess large wings that they beat at lower frequencies relative

83 to other insects of comparable body mass e.g. Lepidoptera and Neuroptera (Dudley, 2000)

84 and Orthoptera (Snelling et al., 2012, 2017). Larger wings can produce more force per beat

85 than smaller wings, and therefore fewer beats are needed per unit time. Moreover, larger

86 wings afford lower wing loadings for insects of the same body mass, so wingbeat frequency

87 may be reduced further. It is possible then that flight-associated morphometrics, such as wing

88 area, can be used to predict wingbeat frequency and characterize flight for different groups of

89 insect using the same stroke strategy (i.e. conventional wingbeat or clap-fling).

91 Flight morphology and wingbeat frequency are dependent on the aerodynamic needs of the insect according to their ecological niche and oxygen consumption increases with wingbeat 93 frequency (Bartholomew and Casey, 1978). Species with similar wing loadings may have 94 different wingbeat frequencies based on the flight velocity required to fulfil their ecological role. 95 Substantial variation in wingbeat frequency and flight morphology as a product of ecological needs also exists within orders, such as the differences between Sphingidae and Nymphalidae

97 (Lepidoptera), where sphingids have small wings, rapid beat frequencies and very fast flight, 98 whilst nymphalids have much larger wings and lower wingbeat frequencies, usually flying at 99 overall slower speeds (Dudley, 2000). Such variation could conceal relationships between 100 flight-associated morphometrics and wingbeat frequency across higher taxonomic levels, 101 decreasing the overall level of phylogenetic grouping of flight strategy. 
103 Order-level taxonomic relationships to these flight-associated morphometrics have been 104 studied before (see Byrne et al., 1988; Dudley, 2000) but meta-analyses suffer from 105 differences in both ambient conditions and methods of measuring wingbeat frequency 106 between studies that may confuse relationships. For example, acoustic methods, 107 stroboscopes, and high-speed cameras were used across studies incorporated into Dudley 108 (2000) and Byrne et al.'s (1988) meta-analyses. Chadwick (1939) suggested stroboscopic 109 methods are difficult to use effectively to glean kinematic data in insects because of the slight 110 variations in wingbeat frequency and movements of the specimen during testing, making 111 visualisation of the wing at the frequency of the strobe light challenging and Unwin and 112 Ellington (1979) suggested picking up acoustic signals of smaller species difficult even with 113 highly sensitive microphones. Both stroboscopic (e.g. Chen et al., 2014) and acoustic (e.g. 114 Raman et al., 2007) methods have, however, been used successfully to measure wingbeat 115 frequency in insects since advancement in the quality of measurement instruments (i,e, optical tachometers and microphones). Nevertheless, stroboscopic/optical and acoustic methods are not absolute measures of wingbeat frequency. High-speed cameras, in contrast, allow the recording of a temporally magnified visual depiction of the motion of insect wings. The reliability of the methods used in studies incorporated into important meta-analyses varies because of the problems faced when the technology was less well developed. Furthermore, temperatures vary from $7-25^{\circ} \mathrm{C}$ between studies used in previous meta-analyses. Insect wingbeat frequency has been shown to increase with higher temperatures (Unwin and Corbet, 1984; Oertli, 1989) and, therefore, meta-analyses of the relationships between measured characteristics may be confounded. An experimental approach using high-speed cameras in controlled conditions recording flight in species across several orders has not previously been done. Using common UK species of insect, relationships between body mass, wing length, wing area, wing loading and wingbeat frequency were investigated to determine if flight strategies could be broadly characterized between different orders of insect. 


\section{MATERIALS AND METHODS}

131 Study specimens

132 Adult insects were caught using either sweep net (EFE \& GB Nets, Totnes, Devon, UK 133 handle length $=0.3 \mathrm{~m}$; net diameter $=0.5 \mathrm{~m}$; net depth $=0.7 \mathrm{~m})$, pooter (NHBS, Totnes, Devon, 134 UK - barrel diameter $=30 \mathrm{~mm}$, length $=55 \mathrm{~mm}$, suction tube diameter $=5 \mathrm{~mm}$ ), or hand 135 collected into small sampling pots (varying sizes) within a $20 \mathrm{~km}$ radius of Harper Adams 136 University, Shropshire, UK (latitude $\sim 52.772^{\circ} \mathrm{N}$, longitude $\sim 2.411^{\circ} \mathrm{W}$ ) over the course of June 137 138 and July, 2017. In total, 112 specimens across 102 species in 10 orders were used in the analysis.

$140 \quad$ Filming area and conditions

141 Filming took place inside a Fitotron ${ }^{\circledR}$ Standard Growth Room unit (Weiss Technik, Ebbw Vale, 142 UK) set to a constant $20^{\circ} \mathrm{C}$ and $60 \%$ relative humidity. This temperature was selected to film 143 flight behaviour of insects in standardised conditions and is unlikely to represent an extreme 144 for tested species, which were all collected during summer days and therefore active within $\sim \pm 5^{\circ} \mathrm{C}$ of the ambient temperature used. Ambient lighting intensity was $280 \mu \mathrm{mol} \mathrm{m}^{-2} \mathrm{~s}^{-1}$ inside the Fitotron $®$ unit and no other external light source was used. A flight box made of 6 transparent Perspex® panels, measuring $30 \times 30 \times 30 \mathrm{~cm}$ once constructed, was used to contain flights of the specimens whilst filming. Study specimens were introduced to the flight box either via a $2.5 \mathrm{~cm}$ diameter aperture made in the centre of one of the panels by offering up an open test tube containing a specimen, or, for larger specimens, the entire panel could be removed and the specimen introduced. 
154 Each specimen was filmed 2-5 times using an FPS1000HD monochromatic high-speed 155 camera (The Slow Motion Camera Company, London, UK). Specimens were filmed each time 156 during free flight. For each flight recorded, the camera was handheld in order to track insects 157 in free flight. This helped increase total length of each video and thus more reliably count wingbeats. Across videos, insects were filmed from various angles, but this did not affect video analysis. Sufficient video footage was gathered in $<10$ minutes for each specimen.

Morphological measurements

Specimens were killed in a killing jar (a jar with a base of plaster of Paris to which ethyl acetate was intermittently added when needed) after the last video was recorded and immediately weighed using a precision balance (Cahn C-33 Microbalance, Cerritos, California, USA). The functional wing (in insects with only one pair of functional wings e.g. Diptera and Coleoptera) or wing couple on the right side (i.e. the fore- and hindwing on the right side of the insect viewed dorsally) was removed by dissection under a stereo microscope and forewing length (henceforth wing length) was measured using a pair of digital calipers $(0.01 \mathrm{~mm}$ precision), measured from the base of the forewing to the most distal tip. A photo was taken of the dissected wing couple using a microscope camera making sure the wings were perpendicular to the camera lens. Wing area was measured in ImageJ version 1.49 (Schindelin et al., 2012) by using the photo and following the ImageJ process for measuring leaf area (Reinking, 2007) as in previous studies on insect wings (e.g. Outomuro et al., 2013); the wing area value was multiplied by 2 to quantify total wing area assuming symmetry. Wing loading was determined by dividing body mass by total wing area.

Video analysis

Videos were first converted into a viewable format using ImageJ, where video frames-persecond (FPS) was then altered to allow individual wingbeats to be clearly visible. A wingbeat 
was judged to be both a full downstroke and full upstroke, terminating at pronation before the next wingbeat (Fig. 1), and in all groups except for Odonata, fore- and hindwings beat at the same time. For odonates, forewing and hindwing pairs were measured separately then the mean was calculated; the difference between the wing pairs did not exceed 2 beats in any of the odonate specimens. Sections of videos were carefully selected to represent free-flight, omitting wingbeats immediately after take-off until a more regular rhythm was observed, which was usually more rapid. The number of wingbeats $n_{v}$ during free-flight was counted for each video. Equation 1 was used to determine the wingbeat frequency $n(\mathrm{~Hz})$ from each video where $t_{v}$ is the length of the video in seconds, and $f_{m}$ is the multiplication factor (the factor that describes by how much time is magnified in each video), which is calculated by dividing filming FPS by video playback FPS. All species were filmed at 1000 FPS except for 6 species of nematoceran Diptera, which were filmed at 2000 FPS.

\section{Statistical Analysis}

Statistical analysis was conducted using $R$ version 3.4.1. "Single Candle" ( $R$ Core Team, 2017) with packages MASS (Venebles and Ripley, 2002), ggplot2 (Wickham, 2009), caret (Kuhn, 2017), hydroGOF (Zambrano-Bigiarini, 2014), relaimpo (Grömping, 2006), and gridExtra (Auguie, 2016) used. Both simple and multiple linear regression analyses were conducted to determine the relationships between morphological variables and wingbeat frequency. Data were log-transformed to reduce skew and allow analysis by linear regression. To better measure the level of phylogenetic clustering of flight strategy, a principal component analysis (PCA) was conducted.

\section{RESULTS}


205 Table 1 compiles the range and mean statistics for morphological measurements and 206 wingbeat frequency in each sampled order. Across all 112 specimens, wingbeat frequency 207 covered a range between 12.468 to $557.351 \mathrm{~Hz}(\bar{x}=121.588$, sd $=92.679$, se = 8.767), body 208 mass a range of 0.0003 to $2.245 \mathrm{~g}(\bar{x}=0.097, \mathrm{sd}=0.256$, se $=0.024)$, wing length a range of 2090.172 to $5.214 \mathrm{~cm}(\bar{x}=1.184, \mathrm{sd}=0.919$, se $=0.087)$, wing area a range of 0.022 to 23.362 $210 \mathrm{~cm}^{2}(\bar{x}=2.022, \mathrm{sd}=4.088, \mathrm{se}=0.386)$, and wing loading a range of 0.0028 to $0.245 \mathrm{~g} / \mathrm{cm}^{2}$ $211(\bar{x}=0.061, \mathrm{sd}=0.059, \mathrm{se}=0.006)$.

213 These values show that some orders were better sampled than others and in some cases this 214 is reflected in the ranges of different variables recorded. Average values, however, are 215 generally in agreement with expected values for UK insects. Synchronous fliers 216 (Ephemeroptera, Lepidoptera, Mecoptera, Neuroptera, Odonata, Trichoptera) were overall 217 less well sampled than asynchronous fliers (Coleoptera, Diptera, Hemiptera, Hymenoptera) and should be similarly taken into account when considering ranges of variables.

Relationships between morphometrics and wingbeat frequency

Figure 2 shows the relevant linear relationships between the $\log _{10}$ transformed morphometric data. Of these, wing area $\left(\mathrm{cm}^{2}\right)$ was the best predictor of wingbeat frequency $\left(R^{2}=0.59, \mathrm{p}=\right.$ $<0.001)$. The strongest overall linear relationship between all morphometric measurements was between wing length $(\mathrm{cm})$ and wing area $\left(R^{2}=0.93, \mathrm{p}=<0.001\right)$. Body mass explained only $9 \%$ of the variation in wingbeat frequency across specimens $\left(R^{2}=0.09, \mathrm{p}=<0.01\right)$ and represented the poorest predictor of wingbeat frequency across the measured morphometrics.

227 Taxonomic distribution on the graphs (Fig. 2, especially A-D) sees a diffuse but identifiable clustering of the orders most intensively sampled, suggesting that orders may broadly adhere to a specific strategy and some new phylogenetic clustering between wingbeat frequency, 
231 focussed solely on taxonomic grouping in relation to wingbeat frequency and body mass. For

232 example, looking at Figure 2D, Hymenoptera are quite closely clustered at the higher end of 233 the wing loading range and the upper-middle range of wingbeat frequency, denoting that most 234 hymenopterans sampled have small wings relative to their body mass, which they beat at 235 above average frequencies compared to other orders.

237 A multiple regression model using $\log _{10}$ values of wing area $(\beta=-0.034, p=<0.001)$ and body 238 mass $(\beta=0.001, p=<0.001)$, with a fit of $R^{2}=0.84$ was the best overall model predicting 239 wingbeat frequency in insects: wingbeat frequency $=($ wing area * -0.77$)+($ body mass * 0.37$)$ $240+5.56$

A dominance analysis (Azen and Budescu, 2003; Grömping, 2006) was conducted to determine the relative importance of the explanatory variables to the response variable in the model and showed that body mass and wing area explained $17.3 \%$ and $67.2 \%$ of the change in wingbeat frequency, respectively.

Phylogenetic clustering of flight strategy

Wingbeat frequency and morphometric variables for all specimens were reduced to a dataset summarising the variance and covariance between each using a Principle Component Analysis (PCA). Initial eigenvalues indicated the first two principle components explained $64.039 \%$ and $33.291 \%$ of the data, respectively ( $97.331 \%$ cumulatively). Dimension 1 is mainly loaded towards wing area (30.417\%), wing length $(30.073 \%)$, body mass $(22.882 \%)$, and wing loading $(16.388 \%)$, whereas Dimension 2 is mainly loaded towards wing loading 254 (58.325\%), wingbeat frequency (24.979\%), and body mass (15.821\%). Having determined the 255 loadings, a PCA biplot was produced to view the relationship between variables and whether 
insect orders were clustered on the graph. Figure 3 reveals that most insect specimens are in close proximity to their associated centroid (the mean value of the $\mathrm{x}$ and $\mathrm{y}$ coordinates for each order), shown by the ellipses, which represent one standard deviation along each axis and is rotated toward the direction of maximum spread of the point cloud. This strongly suggests that flight strategy is well conserved at the order level.

\section{DISCUSSION}

Phylogenetic clustering apparent in this study broadly agrees with results from previous metaanalyses (Byrne et al., 1988; Dudley, 2000). Past research looking at differences in wingbeat frequency and flight-associated morphometrics are, therefore, experimentally validated by the present study through the use of high-speed filming. However, although all measured characteristics significantly affected wingbeat frequency, body mass did not show as clear a relationship to it as in previous meta-analysis (Dudley, 2000). This is likely because of the lack of specimen variation in the present study, compared to the very high number of different specimens across a much broader body mass range in the meta-analysis (Dudley, 2000). Indeed, previous meta-analyses included species from a much wider geographical range, incorporating studies from many different countries and ecosystems, including those from tropical forests.

Wing length and wing area are both able to predict wingbeat frequency moderately accurately, explaining $42 \%$ and $59 \%$ of its variation, respectively. Wing length may affect wingbeat frequency as a product of increasing body mass, where larger insects have slightly longer wings to offset the lower wingbeat frequency and maintain good advance ratios (Vogel, 2013), though this is also connected to wing area (Fig. 2E). Area of the wing generally increases with body mass to accommodate the greater level of lift generation required and longer wings tend to have a greater area than shorter ones. Thus, an increased area means fewer beats are 
necessary per unit time to generate the same amount of lift. This is supported by the positive relationship between wing loading and wingbeat frequency, where heavily loaded wings are generally beaten more rapidly to generate enough lift. Relatively heavily loaded wings must keep a weight aloft with a reduced area and are associated with larger insects (Fig. 2F) because wing area, proportional to the square of body length, cannot keep pace with body mass, proportional to the cube of body length, as insect size increases (Bartholomew and Heinrich, 1973; Byrne et al., 1988; Ennos, 1989; Dudley, 2000; Vogel, 2013). Despite this, heavier insects tended to also have lower wingbeat frequencies (Fig. 2C). Whilst initially paradoxical that heavier insects with greater wing loading beat their wings relatively less frequently, this is because smaller insects must overcome the increasingly viscous forces of air at small scales, greater relative drag, and the greater effect of the wind on their direction by beating their wings comparatively faster (Dudley, 2000; Alexander, 2002; Vogel, 2013) and because the oscillatory frequency of the thorax is inversely dependent on its size, which directly influences wingbeat frequency in asynchronous fliers (Pringle, 1949, 1967; Dickinson and Tu, 1997; Dudley, 2000).

The best overall model explaining the variation in wingbeat frequency incorporated body mass and wing area, the relative importances of which were $17.3 \%$ and $67.2 \%$, respectively. This suggests that despite the weak linear relationship between body mass and wingbeat frequency, together with wing area the variables can explain $84 \%$ of the variation in wingbeat frequency. These findings support previous agreement (Jensen, 1956; Ellington, 1984b-c, 1999; Dudley, 1990, 2000; Alexander, 2002) that wingbeat frequency is in large part dependent on wing area and body mass.

Palaeopterous insects using direct flight muscles and neopterous insects using synchronous flight muscles show generally lower wingbeat frequencies than insects with asynchronous 
flight muscles (Figure 2) and these two groups are further clustered in Figure 3 (Neuroptera, Lepidoptera, Odonata - bottom right; asynchronous fliers - middle/top left). The weak relationship between wingbeat frequency and body mass in the present study as well as past meta-analyses may arise because of the differences in scaling between these groups. Insects with indirect synchronous flight muscles conduct wingbeats by single nerve impulses to the tergosternal (wing depressor) and dorsal-longitudinal (wing elevator) muscles. Thus, the wingbeat frequency of insects with synchronous musculature is determined by the frequency of nervous stimulation to the muscles. In contrast, insects that possess asynchronous muscles have essentially random nervous stimulation relative to the wingbeat frequency (Dickinson and Tu, 1997). Wingbeat frequency in asynchronous fliers is determined primarily by the resonant features of the pterothoracic apparatus to maximise efficiency of energy expenditure (Pringle, 1949; Dickinson and Tu, 1997), as well as behavioural changes during rapid manoeuvring (Nachtigall and Wilson, 1967). Asynchronous muscles are stretch-activated (Pringle, 1949, 1967) by their antagonistic pair within the pterothorax and are therefore dependent on mechanical loading. The inertial load of the whole thorax-wing system must increase with body mass and wingbeat frequency has been shown to vary inversely with wing inertia (Sotavalta, 1952). For asynchronous fliers, scaling of the resonant flight apparatus is therefore especially important, as the oscillatory frequency of the pterothorax is inversely dependent on its size, which directly influences wingbeat frequency (Pringle, 1949, 1967; Dickinson and Tu, 1997; Dudley, 2000). In synchronous fliers, wing amputation experiments to lower wing inertia results in only a relatively small increase in wingbeat frequency in Periplaneta cockroaches and Agrontia moths compared to asynchronous fliers (Roeder, 1951), suggesting wingbeat frequency in synchronous fliers is independent of mechanical load. Thus, asynchronous fliers are more likely to show a stronger scaling relationship between wingbeat frequency and body mass than other insects. No strong inferences relating to scaling differences between synchronous and asynchronous fliers can be made in the present study because Lepidoptera encompassed the only well sampled synchronous fliers. 
336 Orders are shown to be clustered when wingbeat frequency is viewed as a function of one of

337 the other measured morphometrics (Fig. 2A-C), supporting the idea that flight strategy can be 338 generally characterized based on evolutionary history. This may be because of a combination 339 of several factors: 1) species inherit a flight apparatus that can only be changed to a certain 340 extent in a given time to fit a new role/niche e.g. Coleoptera inherit heavy elytra, one pair of 341 functional wings, asynchronous flight muscles, and low flight muscle mass ratio relative to 342 body mass (Marden, 1987; Dudley, 2000) making it unlikely for them to be able to fill the role 343 of an aerial predator but well adapted to infrequent spells of sustained flight; 2) species may 344 need to fly in the same way even though they have different ecological niches, which may 345 increase the level of intra-order clustering because the existing flight apparatus can be used 346 to fulfil the same aerodynamic needs despite interacting with different organisms e.g. 347 Syrphidae and Tabanidae need to fly in similar ways - visiting flowers vs. visiting vertebrate 348 hosts (female tabanids), ability to hover above resources, ability to change direction rapidly to regularly escape predators or swatting etc.; and 3) a specific goal may be achieved in more than one way e.g. Diptera: Asilidae and Odonata are both aerial predators with a high proportion of relative flight muscle mass (Marden, 1987), but likely utilise completely different flight strategies because of their very different inherited flight apparatuses. Combined, these factors suggest that although an inherited flight apparatus is predisposed to certain flight strategies and precludes others, it can be somewhat modified in some instances to fit new ecological niches or maintained if aerodynamic needs do not change with differing ecological interactions. Ultimately, this may improve levels of flight strategy conservation at the order level.

Order-level flight strategies may have interesting energetic, ecological, and evolutionary implications though intra-order exceptions exist where some groups fly in unconventional ways. For example, flies are very light to medium weight with high wingbeat frequencies, 
medium to low wing area and wing length, and medium to high wing loading (Fig. 2A-D). These attributes afford flies the ability to fly quickly, perform complex aerobatic manoeuvres and to hover, conferring obvious ecological advantages to certain groups. Mosquitos and chironomids, however, possess wingbeat frequencies that are unusually high, and wing loadings that are unusually low relative to other Diptera (Table S1, Supplementary Information) that likely increases energetic costs of flight substantially, and may be used for acoustic communication during swarming and mating (Neems et al., 1992; Takken et al., 2006; Bomphrey et al., 2017). One potential explanation of this presumably highly energetically expensive trait uncharacteristic of most other members of the order may be related to sexual selection, where males and females "duet" by reaching a common harmonic tone based on their usually different wingbeat frequencies (Cator et al., 2009; Robert, 2009; Bomphrey et al., 2017).

The variation between different clades within orders suggests broad categorization is possible, with infrequent exceptions. For most orders, however, relationships between wingbeat frequency and flight-associated morphometrics show moderately well conserved patterns across the graphs. These align with previous meta-analyses (Byrne et al., 1988; Dudley, 2000) looking at wingbeat frequency in relation to body mass, with the same orders covering the same areas on the graphs (see Fig. 3.3B in Dudley, 2000). The present study therefore provides strong experimental evidence that flight strategy is broadly conserved at the order level, as specimens are generally clustered phylogenetically, and this validates previous metaanalyses investigating wingbeat frequency and flight-associated morphometrics, although there is evidence that some flight strategies show similarity between certain groups. The PCA analysis could though be improved by incorporating other variables, such as relative flight muscle mass, which is shown to be important when considering the ecology of different orders (Marden, 1987; Dudley, 2000). 
389 Energetic and ecological costs and benefits of differing flight behaviours are still poorly known 390 in most insect groups, though some have received attention e.g. Hymenoptera: Apidae: 391 Euglossini (see Casey et al., 1985; Dudley, 1995; Dillon and Dudley, 2004), Lepidoptera: 392 Sphingidae and Saturniidae (Bartholomew and Casey, 1978), Orthoptera: Acrididae (Snelling 393 et al., 2012), and Hymenoptera: Apidae: Bombini (Ellington et al., 1990). Elucidation of the 394 ecological pressures leading to adaptation of specific flight strategies and the energetic costs associated may help illuminate evolutionary trade-offs. These trade-offs are likely to explain the phylogenetic clustering found across flight-associated morphometrics and wingbeat frequency in the present study. Studies that combine quantitative evaluation of insect flight energetics with additional qualitative comparisons between orders can go some way in revealing why different groups utilise different flight strategies (e.g. between bees, moths, and locusts in Snelling et al., 2012). Further work to reveal ecological pressures and energetic costs of broad flight strategies in different orders is therefore required to infer why insect groups fly the way they do.

\section{ACKNOWLEDGEMENTS}

405

The authors would like to thank Danielle Klassen, George Hicks, and Todd Jenkins for technical assistance during flight filming and field work and Aidan Thomas, Joe Roberts, and Todd Jenkins for providing some of the specimens. George Hicks and Todd Jenkins for their assistance with species taxonomy.

\section{COMPETING INTERESTS}

The authors declare no competing or financial interests.

\section{REFERENCES}


414 Alexander, D. E. (1986) Wind tunnel studies of turns by flying dragonflies. Journal of 415 Experimental Biology, 122, 81-98.

416 Alexander, D. E. (2002) Nature's Flyers : Birds, Insects, and the Biomechanics of Flight. The 417 John Hopkins University Press, Baltimore, Maryland, USA.

418 Atkins, M.D. (1960). A study of the flight of the douglas-fir beetle Dendroctonus pseudotsugae 419 Hopk. (Coleoptera: Scolytidae): II. Flight movements. The Canadian Entomologist, 92(12), $420 \quad$ pp.941-954.

421 Auguie, B. (2016) gridExtra: Miscellaneous Functions for "Grid" Graphics. R package version 422 2.2.1. https://CRAN.R-project.org/package=gridExtra

423 Azen, R. and Budescu, D. V. (2003) The dominance analysis approach for comparing 424 predictors in multiple regression. Psychological Methods, 8(2), 129-148.

425 Bartholomew, G. A. and Casey, T. M. (1978) Oxygen consumption of moths during rest, pre426 flight warm-up, and flight in relation to body size and wing morphology. Journal of Experimental 427 Biology, 76, 11-25.

428 Bartholomew, G. A. and Heinrich, B. (1973) A field study of flight temperatures in moths in 429 relation to body weight and wing loading. Journal of Experimental Biology, 58, 123-135.

430 Bomphrey, R. J., Nakata, T., Phillips, N., and Walker, S. M. (2017) Smart wing rotation and 431 trailing-edge vortices enable high frequency mosquito flight. Nature. 544(7648), 92-95.

432 Byrne, D. N., Buchmann, S. L., and Spangler, H. G. (1988) Relationship between wing loading, 433 wingbeat frequency and body mass in homopterous insects. Journal of Experimental Biology, $434135,9-23$.

435 Casey, T. M. and May, M. L. (1985) Flight energetics of euglossine bees in relation to 436 morphology and wing stroke frequency. Journal of Experimental Biology, 116, 271-289. 
437 Cator, L. J., Arthur, B. J., Harrington, L. C. and Hoy, R. R. (2009) Harmonic convergence in

438 the love songs of the dengue vector mosquito. Science. 323(5917), 1077-1079.

439 Chadwick, L. E. (1939) A simple stroboscopic method for the study of insect flight. Psyche. $440 \quad 46(1), 1-8$.

441 Dickinson, M. H. and Tu, M. S. (1997) The function of dipteran flight muscle. Comparative 442 Biochemistry and Physiology, 116(3), 223-238.

443 Dillon, M. E. and Dudley, R. (2004) Allometry of maximum vertical force production during 444 hovering flight of neotropical orchid bees (Apidae: Euglossini). Journal of Experimental 445 Biology, 207, 417-425.

446 Dudley, R. (1990) Biomechanics of flight in neotropical butterflies: morphometrics and 447 kinematics. Journal of Experimental Biology, 150, 37-53.

448 Dudley, R. (1995) Extraordinary flight performance of orchid bees (Apidae: Euglossini) 449 hovering in heliox (80\% He/20\% O2). Journal of Experimental Biology, 198, 1065-1070.

450 Dudley, R. (2000) The Biomechanics of Insect Flight: Form, Function, Evolution. Princeton 451 University Press, Princeton, New Jersey, USA.

452 Ellington, C. P., Machin, K. E. and Casey, T. M. (1990) Oxygen consumption of bumblebees 453 in forward flight. Nature. $347,472-473$.

454 Ellington, C. P. (1984a) The aerodynamics of hovering insect flight. I. The quasi-steady 455 analysis Philosophical Transactions of the Royal Society B, 305, 1-15.

456 Ellington, C. P. (1984b) The aerodynamics of hovering insect flight. II. Morphological 457 parameters. Philosophical Transactions of the Royal Society B, 305, 17-40.

458 Ellington, C. P. (1984c) The aerodynamics of hovering insect flight. III. Kinematics. 459 Philosophical Transactions of the Royal Society B, 305, 41-78. 
460 Ellington, C. P. (1984d) The aerodynamics of hovering insect flight. IV. Aerodynamic 461 mechanisms. Philosophical Transactions of the Royal Society B, 305, 79-113.

462 Ellington, C. P. (1984e) The aerodynamics of hovering insect flight. V. A vortex theory. 463 Philosophical Transactions of the Royal Society B, 305, 115-144.

464 Ellington, C. P. (1984f) The aerodynamics of hovering insect flight. VI. Lift and power 465 requirements. Philosophical Transactions of the Royal Society B, 305, 145-181.

466 Ellington, C. P. (1999) The novel aerodynamics of insect flight: applications to micro-air 467 vehicles. Journal of Experimental Biology, 202, 3439-3448.

468 Ennos, A. R. (1989) Inertial and aerodynamic torques on the wings of Diptera in flight. Journal 469 of Experimental Biology, 142, 87-95.

470 Fry, S. N., Sayaman, R. and Dickinson, M. H. (2003) The aerodynamics of free-flight 471 maneuvers in Drosophila. Science, 300, 495-498.

472 Gilbert, F. S. (1984) Thermoregulation and the structure of swarms in Syrphus ribesii 473 (Syrphidae). Oikos. 42, 249-255.

474 Grömping, U. (2006) Relative importance for linear regression in R: the package relaimpo. 475 Journal of Statistical Software, 17(1), 1-27.

476 Jensen, M. (1956) Biology and physics of locust flight III. The aerodynamics of locust flight. 477 Philosophical Transactions of the Royal Society B, 239, 511-552.

478 Kuhn, M. (2017) caret: Classification and Regression Training. R package version 6.0-76. 479 https://CRAN.R-project.org/package=caret

480 Lehmann, F. and Dickinson, M. H. (1998) The control of wing kinematics and flight forces in 481 fruit flies (Drosophila spp.). Journal of Experimental Biology, 201, 385-401.

482 Marden, J. H. (1987) Maximum lift production during takeoff in flying animals. Journal of 483 Experimental Biology, 130, 235-258. 
484 Nachtigall, W. and Wilson, D. M. (1967) Neuro-muscular control of dipteran flight. Journal of 485 Experimental Biology, 47, 77-97.

486 Neems, R. M., Lazarus, J. and Mclachlan, A. J. (1992) Swarming behaviour in male 487 chironomid midges: a cost-benefit analysis. Behavioural Ecology, 3(4), 285-290.

488 Oertli, J. J. (1989) Relationship of wing beat frequency and temperature during take-off flight 489 in temperate-zone butterflies. Journal of Experimental Biology, 145, 321-338.

490 Outomuro, D., Adams, D. C. and Johansson, F. (2013) Wing shape allometry and 491 aerodynamics in calopterygid damselflies: a comparative approach. BMC Evolutionary 492 Biology, 13(118).

493 Pringle, J. W. S. (1949) The excitation and contraction of the flight muscles of insects. Journal 494 of Physiology, 108, 226-232.

495 Pringle, J. W. S. (1967) The contractile mechanism of insect fibrillar muscle. Progress in 496 Biophysics and Molecular Biology, 17, 1-12.

497 R Core Team (2017) R: A language and environment for statistical computing. R Foundation 498 for Statistical Computing, Vienna, Austria. URL https://www.R-project.org/.

499 Reinking, L. (2007) Examples of image analysis using ImageJ. Online:

500 https://imagej.nih.gov/ij/docs/pdfs/examples.pdf

501 Robert, D. (2009) Insect bioacoustics: mosquitoes make an effort to listen to each other. 502 Current Biology, 19(11), 446-449.

503 Roeder, K. D. (1951) Movements of the thorax and potential chanfes in the thoracic muscles 504 of insects during flight. Biological Bulletin, 100(2), 95-106.

505 Rüppell, G. and Fincke, O. M. (1989) Megaloprepus coerulatus (Pseudostigmatidae) Flug-und 506 Fortpflanzungsverhalten. Flying and reproductive behaviour. Publikationen fur den 507 Wissenschaftlichen Film, Gottingen, ser. 20, no. 10/E 2976, 1-20. 
508 Schindelin, J., Arganda-Carreras, I., Frise, E., Kaynig, V., Longair, M., Pietzsch, T. et al., and 509 Tinevez, J. Y. (2012) Fiji: an open-source platform for biological-image analysis. Nature 510 Methods, 9(7), 676-682.

511 Snelling, E. P., Seymour, R. S., Matthews, P. G. D. and White, C. R. (2012) Maximum 512 metabolic rate, relative lift, wingbeat frequency and stroke amplitude during tethered flight in 513 the adult locust Locusta migratoria. Journal of Experimental Biology, 215, 3317-3323.

514 Snelling, E. P., Duncker, R., Jones, K. K., Fagan-Jeffries, E. P. and Seymour, R. S. (2017) 515 Flight metabolic rate of Locusta migratoria in relation to oxygen partial pressure in atmosphere 516 of varying diffusivity and density. Journal of Experimental Biology, 220, 4432-4439.

517 Sotavalta, O. (1953) Recordings of high wing-stroke and thoracic vibration frequency in some 518 midges. Biological Bulletin 104(3), 439-444.

519 Takken, W., Costantini, C., Dolo, G., Hassanali, A., Sagnon, N. F. and Osir, E. (2006) 520 Mosquito mating behaviour. In: Bridging laboratory and field research for genetic control of 521 disease vectors. Eds. B. G. J. Knots. and C. Louis. Dordrecht: Springer, 183-188.

522 Unwin, D. M. and Corbet, S. A. (1984) Wingbeat frequency, temperature and body size in 523 bees and flies. Physiological Entomology 9, 115-121.

524 Unwin, D. M. and Ellington, C. P. (1979) An optical tachometer for measurement of the wing525 beat frequency of free-flying insects. Journal of Experimental Biology, 82, 377-378.

526 Venables, W. N. and Ripley, B. D. (2002) Modern Applied Statistics with S. Fourth Edition. 527 Springer, New York. ISBN 0-387-95457-0.

528 Vogel, S. (2013) Comparative Biomechanics: Life's Physical World. Princeton University 529 Press, Princeton, New Jersey, USA.

530 Wang, Z. J. (2005) Dissecting insect flight. Annual Review of Fluid Mechanics. 27, 183-210.

531 Wickham, H. (2009) ggplot2: Elegant Graphics for Data Analysis. Springer-Verlag, New York. 
532 Wilkin, P.J. (1991) Instantaneous aerodynamic forces developed by an indian moon moth, 533 Actias selene, in near-hovering flight. Physiological Zoology, 64(1), pp.193-211.

534 Zambrano-Bigiarini, M. (2014) hydroGOF: Goodness-of-fit functions for comparison of 535 simulated and observed hydrological time series. R package version 0.3-8. https://CRAN.R536 project.org/package=hydroGOF

537

538

539

540

541

542

543

544

545

546

547

548

549

550

551

552 
553 Figure 1. Images a-k show a complete wingbeat in the beetle Rutpela maculata 554 (Coleoptera: Cerambycidae); $t$ is time in milliseconds from the start of the wingbeat. a. the 555 end of pronation; b-e. downstroke translation; e-g. supination; h-j. upstroke translation; j-k. 556 pronation.

557

558

559

560

561

562

563

564

565

566

567

568

569

570

571

572

573 
574 Figure 2. Relationships between $\log _{10}$ transformed morphometric variables. a, wingbeat 575 frequency $(\mathrm{Hz})$ as a function of wing length $(\mathrm{cm})$ : wingbeat frequency $=-0.764$ * wing length + $5764.479, R^{2}=0.42, \mathrm{p}=<0.001 ; \mathrm{b}$, wingbeat frequency as a function of wing area $\left(\mathrm{cm}^{2}\right)$ : wingbeat 577 frequency $=-0.413$ * wing area $+4.345, R^{2}=0.59, p=<0.001 ; \mathbf{c}$, wingbeat frequency as a 578 function of body mass $(\mathrm{g})$ : wingbeat frequency $=-0.129 *$ body mass $+4.04, R^{2}=0.09, \mathrm{p}=$ $579<0.01$; d, wingbeat frequency as a function of wing loading $\left(\mathrm{g} / \mathrm{cm}^{2}\right)$ : wingbeat frequency $=$ 5800.385 * wing loading $+5.799, R^{2}=0.29, p=<0.001 ; \mathbf{e}$, wing area as a function of wing length: 581 wing area $=2.105$ * wing length $-0.307, R^{2}=0.93, p=<0.001 ; \mathbf{f}$, wing loading as a function 582 of body mass: wing loading $=0.356$ * body mass $-1.977, R^{2}=0.34, p=<0.001 ; \mathbf{g}$, wing area 583 as a function of body mass: wing area $=0.644$ * body mass $+1.977, R^{2}=0.63, p=<0.001$. 
596 Figure 3. Principle component data for Dimensions 1 and 2, categorised into different 597 insect orders by symbol shape and colour. Small translucent symbols represent 598 specimens and large opaque symbols represent the centroids for each order. The ellipses 599 around each centroid represent one standard deviation along each axis of the associated 600 order and are rotated in the direction of maximum spread. Trichoptera, Ephemeroptera, and 601 Mecoptera lack ellipses because of an insufficient sample size. The Dimension scores show 602 a moderate-high level of clustering of orders in relation to measured variables, as specimens 603 are generally in close proximity to their associated centroid. The black point in the top-right 604 quarter of the graph is the mean direction of the arrows and suggests the variables are on 605 average positively correlated with dimensions 1 and 2.

606

607

608

609

610

611

612

613

614

615

616

617

618 
619 Table 1. Range and mean of wingbeat frequency and associated morphological 620 measurements in each sampled order. Number of species are denoted in parentheses beside 621 sample size in the right-most column.

622

623

624

625

626

627

628

629

630

631

632

633

634

635

636

637

638

639 
640 Supplementary Information

641 Table S1. Wingbeat frequency and morphological measurements of all specimens. Lists

642 specimens by body mass in ascending order. Cells with a "-" denote the specimen failed to

643 be identified to the associated taxonomic rank.

644

645

646

647

648

649

650

651

652

653

654

655

656

657

658

659

660

661 
662 Figure 1.

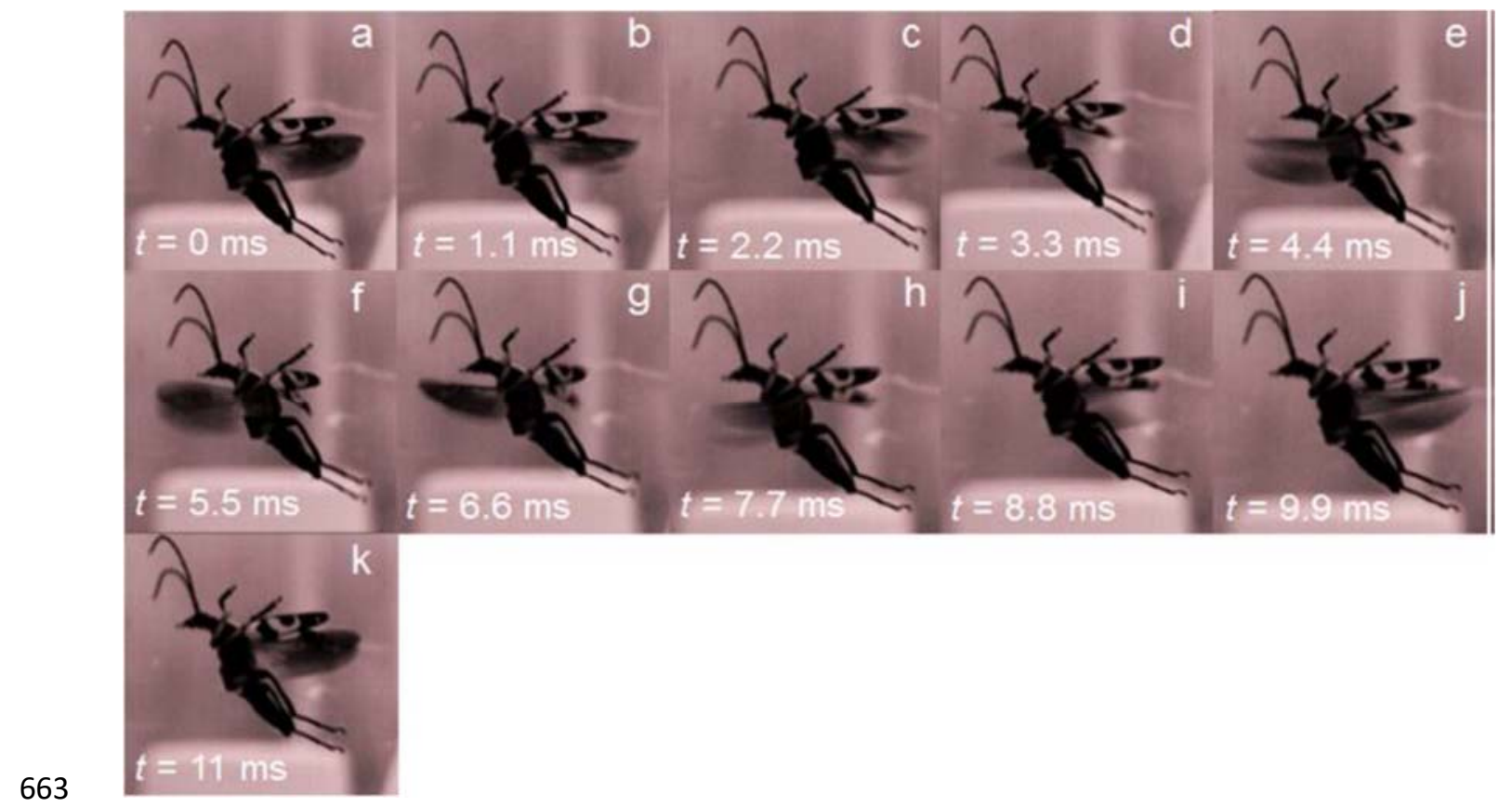

664

665

666

667

668

669

670

671

672

673

674

675 
Figure 2.
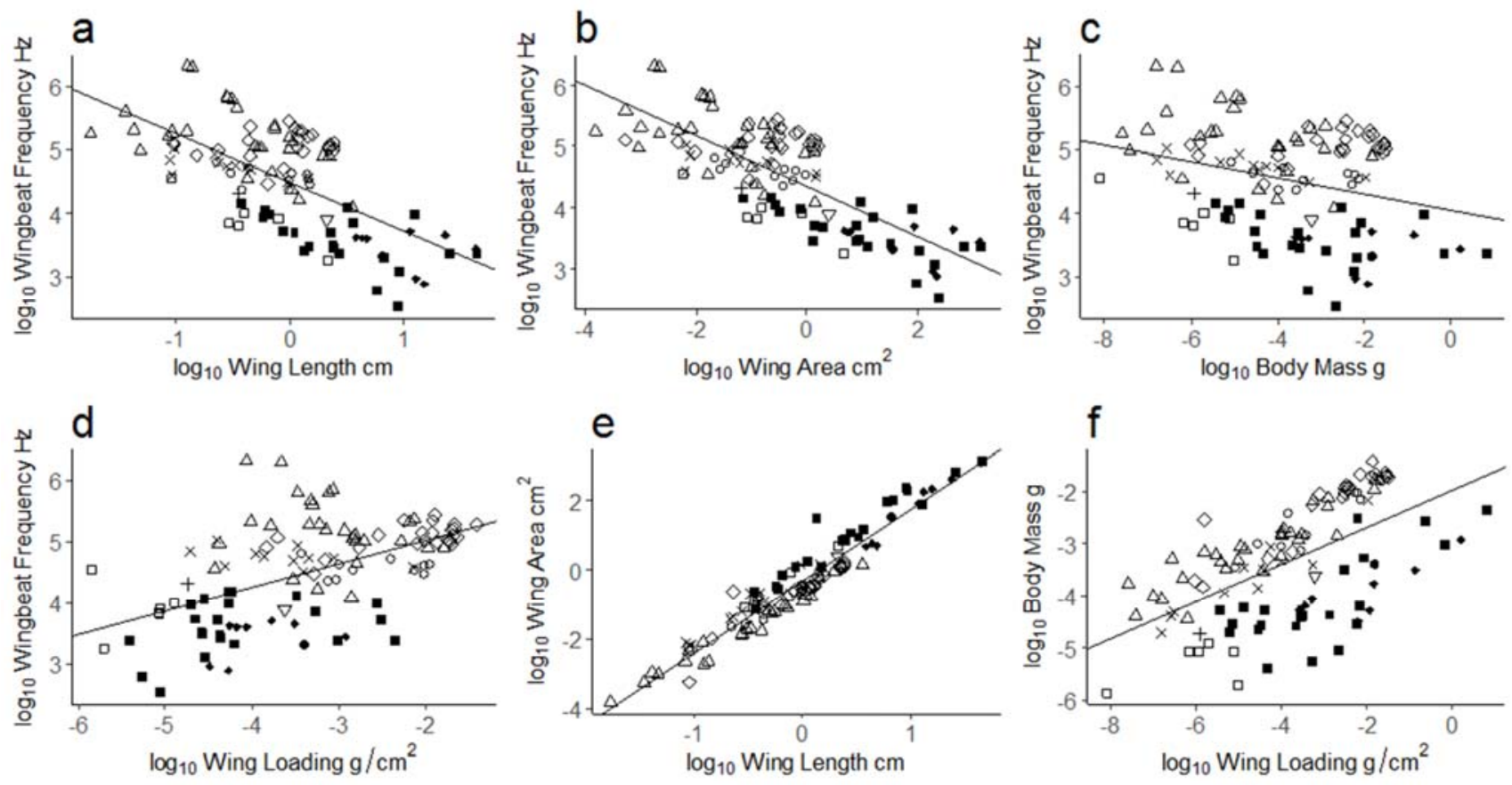

677

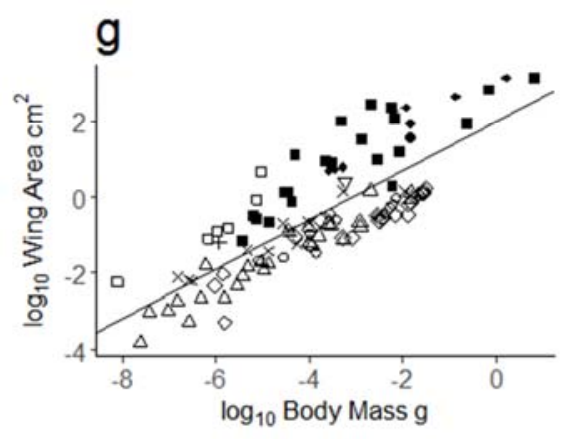

Order
- Coleoptera
$\Delta$ Diptera
+ Ephemeroptera
$X$ Hemiptera
$\checkmark$ Hymenoptera
- Lepidoptera
$\nabla$ Mecoptera
- Neuroptera
- Odonata

678

679

680

681 


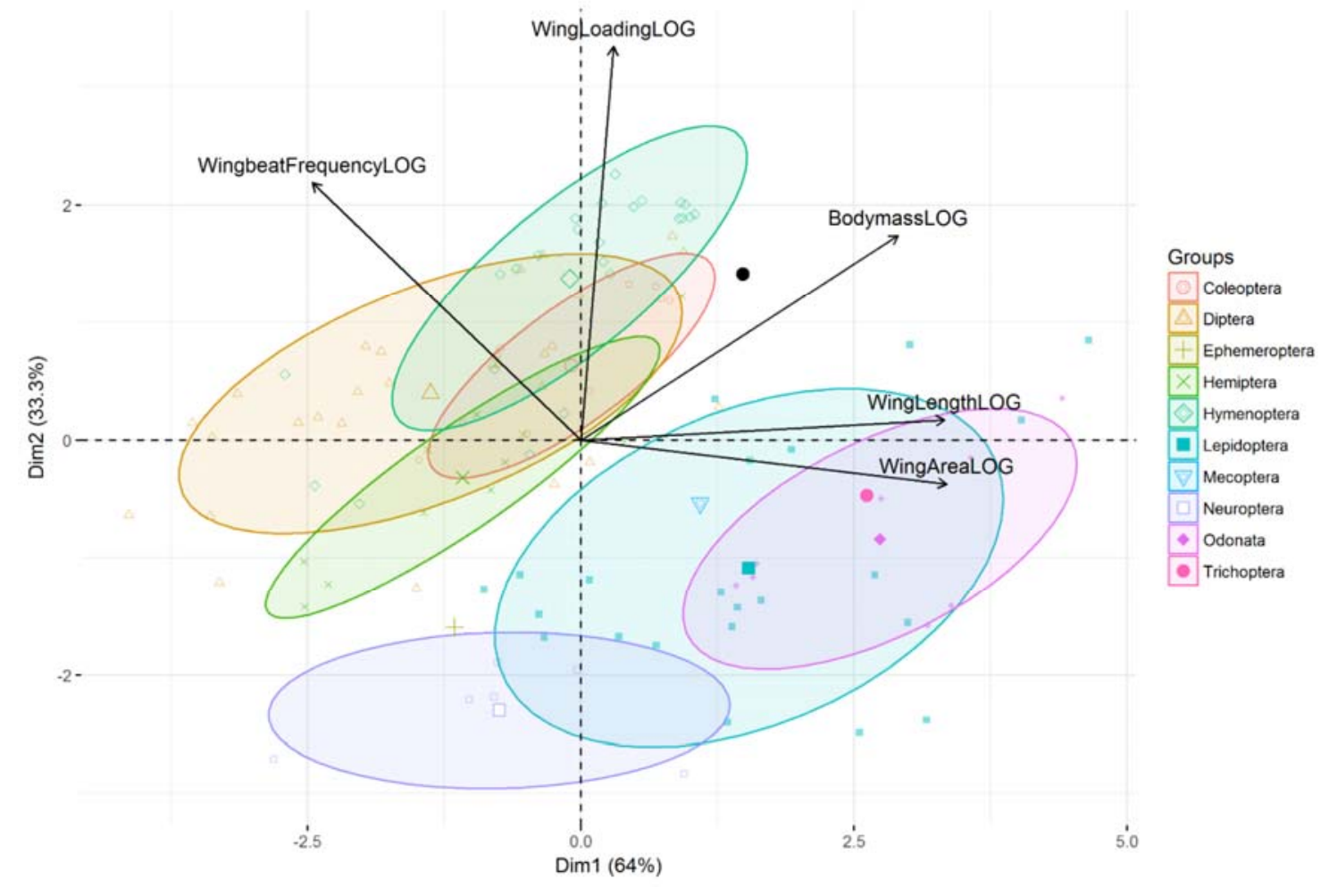

686

687

688

689

690

691

692

693

694

695

696 
Table 1.

\begin{tabular}{|c|c|c|c|c|c|c|c|c|c|c|c|}
\hline \multirow[t]{2}{*}{ ' } & \multicolumn{2}{|c|}{$\begin{array}{l}\text { Wingbeat frequency (mean } \\
\mathrm{Hz} \text { ) }\end{array}$} & \multicolumn{2}{|c|}{ Bodymass (g) } & \multicolumn{2}{|c|}{ Wing length $(\mathrm{cm})$} & \multicolumn{2}{|c|}{ Wing area $\left(\mathrm{cm}^{2}\right)$} & \multicolumn{2}{|c|}{ Wing loading $\left(\mathrm{g} / \mathrm{cm}^{2}\right)$} & \multirow[t]{2}{*}{$\begin{array}{l}\text { Number of } \\
\text { specimens }\end{array}$} \\
\hline & range & mean & range & mean & range & mean & range & mean & range & mean & \\
\hline Coleoptera & $79-123.396$ & 97.512 & $0.0061-0.117$ & 0.0539 & $0.521-1.188$ & 0.898 & $0.19-0.982$ & 0.545 & $0.0321-0.141$ & 0.085 & $10(10)$ \\
\hline Diptera & $59.567-557.351$ & 208.244 & $0.0005-0.162$ & 0.0268 & $0.172-1.739$ & 0.729 & $0.022-1.17$ & 0.327 & $0.0119-0.168$ & 0.0554 & $28(28)$ \\
\hline Ephemeroptera & $\mathrm{n} / \mathrm{a}$ & 75.0454 & $\mathrm{n} / \mathrm{a}$ & 0.0027 & $\mathrm{n} / \mathrm{a}$ & 0.634 & $\mathrm{n} / \mathrm{a}$ & 0.306 & $\mathrm{n} / \mathrm{a}$ & 0.00882 & 1(1) \\
\hline Hemiptera & $90.222-152.247$ & 116.39 & $0.0011-0.14$ & 0.0226 & $0.345-1.185$ & 0.624 & $0.112-1.186$ & 0.445 & $0.009-0.118$ & 0.034 & $11(11)$ \\
\hline Hymenoptera & 87.129 - 230.987 & 163.89 & $0.0024-0.223$ & 0.103 & $0.356-1.48$ & 1.006 & $0.038-1.234$ & 0.64 & $0.022-0.245$ & 0.136 & $24(15)$ \\
\hline Lepidoptera & $12.468-64.566$ & 39.606 & $0.0044-2.24$ & 0.203 & $0.646-5.214$ & 1.792 & $0.318-23.362$ & 5.031 & $0.004-0.096$ & 0.025 & $22(22)$ \\
\hline Mecoptera & $\mathrm{n} / \mathrm{a}$ & 48.885 & $\mathrm{n} / \mathrm{a}$ & 0.0398 & $\mathrm{n} / \mathrm{a}$ & 1.387 & $\mathrm{n} / \mathrm{a}$ & 1.492 & $\mathrm{n} / \mathrm{a}$ & 0.027 & $1(1)$ \\
\hline Neuroptera & $25-923-94.413$ & 52.801 & $0.0003-0.0065$ & 0.0035 & $0.352-1.393$ & 0.757 & $0.106-1.972$ & 0.701 & $0.003-0.007$ & 0.005 & $6(6)$ \\
\hline Odonata & $17.847-40.665$ & 32.331 & $0.0278-1.23$ & 0.27 & $1.795-5.158$ & 3.002 & $1.964-22.784$ & 8.768 & $0.0112-0.054$ & 0.022 & $8(6)$ \\
\hline Trichoptera & $\mathrm{n} / \mathrm{a}$ & 27.515 & $\mathrm{n} / \mathrm{a}$ & 0.159 & $\mathrm{n} / \mathrm{a}$ & 2.267 & $\mathrm{n} / \mathrm{a}$ & 4.738 & $\mathrm{n} / \mathrm{a}$ & 0.0336 & $1(1)$ \\
\hline
\end{tabular}

698

699

700

701

702

703

704

705

706

707

708

709

710 
711 Supplementary Table.

\begin{tabular}{|c|c|c|c|c|c|c|c|c|}
\hline Species & Genus & Family & Order & $\begin{array}{c}\text { Wingbeat frequency } \\
\text { (mean Hz) }\end{array}$ & $\begin{array}{c}\text { Bodymass } \\
\text { (g) }\end{array}$ & $\begin{array}{c}\text { Wing length } \\
\text { (cm) }\end{array}$ & $\begin{array}{c}\text { Wing area } \\
\left(\mathrm{cm}^{2}\right)\end{array}$ & $\begin{array}{c}\text { Wing loading } \\
\left(\mathrm{g} / \mathrm{cm}^{2}\right)\end{array}$ \\
\hline- & Micromus & Hemerobiidae & Neuroptera & 94.413 & 0.0003 & 0.352 & 0.106 & 0.003 \\
\hline- & Syrphus. & Syrphidae & Diptera & 190.860 & 0.0005 & 0.172 & 0.022 & 0.023 \\
\hline- & - & Psychodidae & Diptera & 144.611 & 0.0006 & 0.267 & 0.048 & 0.013 \\
\hline- & - & - & Diptera & 204.355 & 0.0009 & 0.252 & 0.050 & 0.018 \\
\hline- & - & Chironomidae & Diptera & 557.351 & 0.0011 & 0.406 & 0.064 & 0.017 \\
\hline- & - & Miridae & Hemiptera & 127.872 & 0.0011 & 0.345 & 0.122 & 0.009 \\
\hline Thaumatomyia notata & Thaumatomyia & Chloropidae & Diptera & 269.741 & 0.0014 & 0.234 & 0.038 & 0.037 \\
\hline- & - & - & Hemiptera & 152.247 & 0.0014 & 0.358 & 0.114 & 0.012 \\
\hline Uroleucon cirsii & Uroleucon & Aphididae & Hemiptera & 99.603 & 0.0015 & 0.353 & 0.112 & 0.013 \\
\hline- & - & Chironomidae & Diptera & 544.494 & 0.0018 & 0.423 & 0.070 & 0.026 \\
\hline- & - & Tipulidae & Diptera & 94.606 & 0.0020 & 0.687 & 0.168 & 0.012 \\
\hline Hemerobius humulinus & Hemerobius & Hemerobiidae & Neuroptera & 46.583 & 0.0021 & 0.586 & 0.336 & 0.006 \\
\hline- & Torymus & Torymidae & Hymenoptera & 160.011 & 0.0024 & 0.360 & 0.098 & 0.024 \\
\hline Wesmaelius subnebulosis & Wesmaelius & Hemerobiidae & Neuroptera & 45.304 & 0.0026 & 0.640 & 0.416 & 0.006 \\
\hline Centroptilum luteolum & Centroptilum & Baetidae & Ephemeroptera & 75.045 & 0.0027 & 0.634 & 0.306 & 0.009 \\
\hline- & - & Braconidae & Hymenoptera & 136.261 & 0.0029 & 0.438 & 0.134 & 0.022 \\
\hline- & - & Chloropidae & Diptera & 180.050 & 0.0030 & 0.342 & 0.070 & 0.043 \\
\hline- & - & Braconidae & Hymenoptera & 164.443 & 0.0030 & 0.356 & 0.038 & 0.079 \\
\hline- & Wesmaelius & Hemerobiidae & Neuroptera & 54.583 & 0.0033 & 0.666 & 0.444 & 0.007 \\
\hline - & - & - & Diptera & 195.996 & 0.0039 & 0.354 & 0.098 & 0.040 \\
\hline
\end{tabular}




\begin{tabular}{|c|c|c|c|c|c|c|c|c|}
\hline- & - & Syrphidae & Diptera & 198.890 & 0.0044 & 0.403 & 0.124 & 0.035 \\
\hline Pseudargyrotoza conwagana & Pseudargyrotoza & Tortricidae & Lepidoptera & 64.246 & 0.0044 & 0.653 & 0.318 & 0.014 \\
\hline- & - & Miridae & Hemiptera & 120.832 & 0.0048 & 0.530 & 0.250 & 0.019 \\
\hline Culex pipiens & Culex & Culicidae & Diptera & 334.037 & 0.0049 & 0.578 & 0.158 & 0.031 \\
\hline- & - & Tortricidae & Lepidoptera & 52.214 & 0.0055 & 0.785 & 0.612 & 0.009 \\
\hline- & - & Crambidae & Lepidoptera & 57.948 & 0.0059 & 0.799 & 0.562 & 0.010 \\
\hline Micromus angulatus & Micromus & Hemerobiidae & Neuroptera & 50.000 & 0.0059 & 0.904 & 0.932 & 0.006 \\
\hline Oulema melanopus & Oulema & Chrysomelidae & Coleoptera & 123.398 & 0.0061 & 0.521 & 0.190 & 0.032 \\
\hline Chrysoperla carnea & Chrysoperla & Chrysopidae & Neuroptera & 25.923 & 0.0065 & 1.393 & 1.972 & 0.003 \\
\hline Aedes cantans & Aedes & Culicidae & Diptera & 286.949 & 0.0066 & 0.627 & 0.182 & 0.036 \\
\hline Culiseta annulata & Culiseta & Culicidae & Diptera & 344.160 & 0.0070 & 0.572 & 0.150 & 0.047 \\
\hline Macrolophus sp. & Macrolophus & Miridae & Hemiptera & 139.717 & 0.0076 & 0.515 & 0.244 & 0.031 \\
\hline Lobesia abscisana & Lobesia & Tortricidae & Lepidoptera & 64.566 & 0.0076 & 0.646 & 0.526 & 0.014 \\
\hline Culiseta annulata & Culiseta & Culicidae & Diptera & 331.157 & 0.0077 & 0.602 & 0.174 & 0.044 \\
\hline- & - & - & Hemiptera & 116.865 & 0.0104 & 0.619 & 0.490 & 0.021 \\
\hline Propylea 14-punctata & Propylea & Coccinellidae & Coleoptera & 102.427 & 0.0105 & 0.589 & 0.210 & 0.050 \\
\hline Pasiphila rectangulata & Pasiphila & Geometridae & Lepidoptera & 41.358 & 0.0107 & 0.938 & 1.132 & 0.009 \\
\hline Pterophorus pentadactyla & Pterophorus & Pterophoridae & Lepidoptera & 32.333 & 0.0114 & 1.192 & 1.120 & 0.010 \\
\hline Nephrotoma flavescens & Nephrotoma & Tipulidae & Diptera & 79.470 & 0.0118 & 1.015 & 0.402 & 0.029 \\
\hline- & - & Miridae & Hemiptera & 108.171 & 0.0119 & 0.710 & 0.402 & 0.030 \\
\hline Pandemis cerasana & Pandemis & Tortricidae & Lepidoptera & 54.184 & 0.0124 & 0.835 & 0.890 & 0.014 \\
\hline Athalia scuttelariae & Athalia & Tenthredinidae & Hymenoptera & 87.129 & 0.0132 & 0.826 & 0.352 & 0.038 \\
\hline Xanthorhoe montanata & Xanthorhoe & Geometridae & Lepidoptera & 29.243 & 0.0133 & 1.561 & 2.980 & 0.004 \\
\hline Lygus rugulipennis & Lygus & Miridae & Hemiptera & 115.183 & 0.0140 & 0.574 & 0.298 & 0.047 \\
\hline
\end{tabular}




\begin{tabular}{|c|c|c|c|c|c|c|c|c|}
\hline Nephrotoma quadrifaria & Nephrotoma & Tipulidae & Diptera & 67.360 & 0.0181 & 1.084 & 0.464 & 0.039 \\
\hline Rhagonycha fulva & Rhagonycha & Catharidae & Coleoptera & 79.712 & 0.0183 & 0.653 & 0.380 & 0.048 \\
\hline Chloromyia formosa & Chloromyia & Stratiomyidae & Diptera & 156.043 & 0.0183 & 0.736 & 0.312 & 0.059 \\
\hline Haematopota pluvialis & Haematopota & Tabanidae & Diptera & 151.568 & 0.0183 & 0.779 & 0.302 & 0.061 \\
\hline- & - & - & Hemiptera & 112.917 & 0.0184 & 0.682 & 0.518 & 0.036 \\
\hline- & - & Vespidae: Eumeninae & Hymenoptera & 135.597 & 0.0184 & 0.703 & 0.292 & 0.063 \\
\hline - & - & Empididae & Diptera & 151.321 & 0.0193 & 0.759 & 0.288 & 0.067 \\
\hline Oedemera nobilis & Oedemera & Oedemeridae & Coleoptera & 112.656 & 0.0210 & 0.698 & 0.232 & 0.091 \\
\hline Scathophaga stercoraria & Scathophaga & Scathophagidae & Diptera & 104.015 & 0.0224 & 0.854 & 0.366 & 0.061 \\
\hline - & - & Ichneumonidae & Hymenoptera & 110.116 & 0.0233 & 0.942 & 0.546 & 0.043 \\
\hline Manulea lurideola & Manulea & Erebidae & Lepidoptera & 33.095 & 0.0258 & 1.470 & 2.542 & 0.010 \\
\hline Syrphus ribesii & Syrphus & Syrphidae & Diptera & 177.908 & 0.0273 & 0.994 & 0.512 & 0.053 \\
\hline Coenagrion puella & Coenagrion & Coenagrionidae & Odonata & 37.495 & 0.0277 & 1.795 & 1.964 & 0.014 \\
\hline Harmonia axyridis & Harmonia & Coccinellidae & Coleoptera & 79.000 & 0.0283 & 0.993 & 0.644 & 0.044 \\
\hline Anania hortulata & Anania & Crambidae & Lepidoptera & 40.996 & 0.0293 & 1.448 & 2.410 & 0.012 \\
\hline Episyrphus balteatus & Episyrphus & Syrphidae & Diptera & 166.057 & 0.0294 & 1.025 & 0.488 & 0.060 \\
\hline Idaea aversata & Idaea & Geometridae & Lepidoptera & 32.088 & 0.0303 & 1.471 & 2.420 & 0.013 \\
\hline Coenagrion puella & Coenagrion & Coenagrionidae & Odonata & 36.691 & 0.0316 & 1.984 & 2.072 & 0.015 \\
\hline- & Aphodius & Scarabaeidae & Coleoptera & 93.054 & 0.0327 & 0.987 & 0.560 & 0.058 \\
\hline Aphantopus hyperantus & Aphantopus & Nymphalidae & Lepidoptera & 16.014 & 0.0373 & 2.168 & 7.262 & 0.005 \\
\hline Coenagrion puella & Coenagrion & Coenagrionidae & Odonata & 36.839 & 0.0374 & 1.902 & 2.190 & 0.017 \\
\hline- & Andrena & Apidae & Hymenoptera & 213.815 & 0.0376 & 0.703 & 0.352 & 0.107 \\
\hline - & - & - & Hemiptera & 90.222 & 0.0383 & 0.989 & 1.164 & 0.033 \\
\hline- & - & Syrphidae & Diptera & 208.540 & 0.0385 & 0.872 & 0.340 & 0.113 \\
\hline
\end{tabular}




\begin{tabular}{|c|c|c|c|c|c|c|c|c|}
\hline Panorpa communis & Panorpa & Panorpidae & Mecoptera & 48.885 & 0.0398 & 1.387 & 1.492 & 0.027 \\
\hline- & Andrena & Apidae & Hymenoptera & 172.581 & 0.0453 & 0.690 & 0.346 & 0.131 \\
\hline- & Sarcophaga & Sarcophagidae & Diptera & 149.643 & 0.0540 & 0.995 & 0.526 & 0.103 \\
\hline Calliphora vomitoria & Calliphora & Calliforidae & Diptera & 214.835 & 0.0549 & 0.874 & 0.460 & 0.119 \\
\hline Hypena proboscidalis & Hypena & Noctuidae & Lepidoptera & 30.587 & 0.0565 & 1.137 & 4.496 & 0.013 \\
\hline- & Tipula & Tipulidae & Diptera & 59.567 & 0.0676 & 1.739 & 1.170 & 0.058 \\
\hline Pieris brassicae & Pieris & Pieridae & Lepidoptera & 12.468 & 0.0691 & 2.593 & 10.992 & 0.006 \\
\hline Vespula germanica & Vespula & Vespidae & Hymenoptera & 145.156 & 0.0769 & 1.126 & 0.628 & 0.122 \\
\hline Ectemnius cavifrons & Ectemnius & Crabronidae & Hymenoptera & 210.688 & 0.0800 & 1.037 & 0.542 & 0.148 \\
\hline - & Zygaena & Zygaenidae & Lepidoptera & 60.595 & 0.0804 & 1.669 & 2.640 & 0.030 \\
\hline Vespula germanica & Vespula & Vespidae & Hymenoptera & 152.006 & 0.0818 & 1.061 & 0.610 & 0.134 \\
\hline Vespula germanica & Vespula & Vespidae & Hymenoptera & 146.908 & 0.0833 & 0.530 & 0.536 & 0.155 \\
\hline Vespula vulgaris & Vespula & Vespidae & Hymenoptera & 173.277 & 0.0874 & 1.081 & 0.598 & 0.146 \\
\hline Apis mellifera & Apis & Apidae & Hymenoptera & 230.987 & 0.0886 & 0.995 & 0.588 & 0.151 \\
\hline- & Aphodius & Scarabaeidae & Coleoptera & 103.159 & 0.0929 & 1.018 & 0.658 & 0.141 \\
\hline Rutpela maculata & Rutpela & Cerambicidae & Coleoptera & 86.840 & 0.1026 & 1.188 & 0.768 & 0.134 \\
\hline Geometra papilionaria & Geometra & Geometridae & Lepidoptera & 22.023 & 0.1071 & 2.632 & 10.194 & 0.011 \\
\hline Chrysoteuchia culmella & Chrysoteuchia & Crambidae & Lepidoptera & 40.626 & 0.1090 & 1.041 & 1.330 & 0.082 \\
\hline Calopteryx splendens & Calopteryx & Calopterygidae & Odonata & 19.318 & 0.1092 & 3.054 & 9.760 & 0.011 \\
\hline- & Aphodius & Scarabaeidae & Coleoptera & 101.111 & 0.1095 & 1.161 & 0.822 & 0.133 \\
\hline Polygonia c-album & Polygonia & Nymphalidae & Lepidoptera & 27.501 & 0.1145 & 2.298 & 7.696 & 0.015 \\
\hline Bombus pascuorum & Bombus & Apidae & Hymenoptera & 198.274 & 0.1166 & 1.074 & 0.614 & 0.190 \\
\hline Leptura quadrifasciata & Leptura & Cerambicidae & Coleoptera & 93.768 & 0.1173 & 1.173 & 0.982 & 0.119 \\
\hline Orthosia gothica & Orthosia & Noctuidae & Lepidoptera & 47.053 & 0.1253 & 1.753 & 3.260 & 0.038 \\
\hline
\end{tabular}




\begin{tabular}{|c|c|c|c|c|c|c|c|c|}
\hline Pentatoma rufipes & Pentatoma & Pentatomidae & Hemiptera & 96.667 & 0.1397 & 1.185 & 1.186 & 0.118 \\
\hline Calopteryx virgo & Calopteryx & Calopterygidae & Odonata & 17.847 & 0.1457 & 3.287 & 10.466 & 0.014 \\
\hline 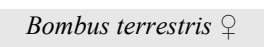 & Bombus & Apidae & Hymenoptera & 183.029 & 0.1504 & 1.171 & 0.818 & 0.184 \\
\hline Bombus lapidarius & Bombus & Apidae & Hymenoptera & 199.547 & 0.1536 & 1.114 & 0.626 & 0.245 \\
\hline Phryganea grandis & Phryganea & Phryganeidae & Trichoptera & 27.515 & 0.1590 & 2.267 & 4.738 & 0.034 \\
\hline Sympetrum striolatum & Sympetrum & Libellulidae & Odonata & 40.665 & 0.1595 & 2.894 & 6.944 & 0.023 \\
\hline Volucella pellucens & Volucella & Syrphidae & Diptera & 134.179 & 0.1613 & 1.418 & 1.152 & 0.140 \\
\hline Volucella bombylans & Volucella & Syrphidae & Diptera & 133.078 & 0.1624 & 1.337 & 0.966 & 0.168 \\
\hline Bombus terrestris + & Bombus & Apidae & Hymenoptera & 186.521 & 0.1641 & 1.229 & 0.864 & 0.190 \\
\hline Bombus terrestris 우 & Bombus & Apidae & Hymenoptera & 152.625 & 0.1854 & 1.436 & 1.048 & 0.177 \\
\hline Bombus terrestris $\bigcirc$ & Bombus & Apidae & Hymenoptera & 153.182 & 0.1972 & 1.422 & 1.128 & 0.175 \\
\hline Bombus terrestris 우 & Bombus & Apidae & Hymenoptera & 144.712 & 0.2081 & 1.454 & 1.134 & 0.184 \\
\hline Bombus terrestris + & Bombus & Apidae & Hymenoptera & 161.815 & 0.2125 & 1.425 & 1.086 & 0.196 \\
\hline Bombus terrestris $\hat{\alpha}$ & Bombus & Apidae & Hymenoptera & 165.085 & 0.2154 & 1.480 & 1.152 & 0.187 \\
\hline Bombus terrestris ô & Bombus & Apidae & Hymenoptera & 149.597 & 0.2227 & 1.480 & 1.234 & 0.180 \\
\hline Orthetrum cancellatum & Orthetrum & Libellulidae & Odonata & 38.577 & 0.4176 & 3.944 & 13.960 & 0.030 \\
\hline Deilephila elpenor & Deilephila & Sphingidae & Lepidoptera & 53.715 & 0.5281 & 3.026 & 6.792 & 0.078 \\
\hline Laothoe populi & Laothoe & Sphingidae & Lepidoptera & 29.330 & 0.8449 & 4.085 & 17.152 & 0.049 \\
\hline Aeshna grandis & Aeshna & Aeshnidae & Odonata & 31.214 & 1.2296 & 5.158 & 22.784 & 0.054 \\
\hline Acherontia atropos & Acherontia & Sphingidae & Lepidoptera & 29.160 & 2.2403 & 5.214 & 23.362 & 0.096 \\
\hline
\end{tabular}


715 Equation 1.

716

Equation $1 \quad n=n_{v} \frac{1}{\left(t_{v} / f_{m}\right)}$ 